\title{
The role of surgical resection in primary central nervous system lymphoma: a single-center retrospective analysis of 70 patients
}

Shiqiang Wu, Junwen Wang, Weihua Liu, Feng Hu, Kai Zhao, Wei Jiang, Ting Lei and Kai Shu*

\begin{abstract}
Background: The aim of this study was to evaluate the effect of surgical resection and stereotactic biopsy on the complication rate, progression-free survival (PFS) and overall survival (OS) of 70 patients diagnosed at a single institution with primary central nervous system lymphoma (PCNSL) and to explore the predictors of selection for resection and the prognostic factors of PCNSL.

Methods: A retrospective analysis was performed of 70 patients with PCNSL that was diagnosed by surgical resection or stereotactic brain biopsy in our department from January 2013 to May 2019. We divided the patients into two groups: a resection group $(n=28)$ and a stereotactic biopsy group $(n=42)$. Data on clinical characteristics, imaging findings, complication rates, PFS and OS were retrospectively reviewed and compared between these two groups. We also analysed the predictors of selection for resection and prognostic factors of PCNSL by multivariate analysis.

Results: The median age was $53.3 \pm 14.3$ years, and there was a male predominance with a sex ratio of 1.33:1. The most common clinical manifestation was a headache. The complication rate in the resection group was $10.7 \%$ versus $7.1 \%$ in the stereotactic biopsy group, and there was no statistically significant difference. The rate of improvement in symptoms of the resection group was significantly higher than that of the stereotactic biopsy group. Multivariable analysis identified a single tumour and not involving deep structures as predictors of selection for resection. With a median follow-up of 30 months (range 1-110), the mean OS and PFS of all patients were 16.1 months and 6.2 months, respectively. Patients who underwent surgical resection had a mean OS of 23.4 months and PFS of 8.6 months versus 11.2 months and 4.6 months for those who had a brain biopsy performed. In addition, multivariable analysis showed that not involving deep structures and resection were favourable prognostic factors for PCNSL.

*Correspondence: wushiqiang1013@126.com

Department of Neurosurgery, Tongji hospital, Tongji Medical College, Huazhong University of Science and Technology, 1095\# Jiefang Avenue,

Wuhan 430030, Hubei, China

(c) The Author(s). 2021 Open Access This article is licensed under a Creative Commons Attribution 4.0 International License, which permits use, sharing, adaptation, distribution and reproduction in any medium or format, as long as you give appropriate credit to the original author(s) and the source, provide a link to the Creative Commons licence, and indicate if changes were made. The images or other third party material in this article are included in the article's Creative Commons licence, unless indicated otherwise in a credit line to the material. If material is not included in the article's Creative Commons licence and your intended use is not permitted by statutory regulation or exceeds the permitted use, you will need to obtain permission directly from the copyright holder. To view a copy of this licence, visit http://creativecommons.org/licenses/by/4.0/ The Creative Commons Public Domain Dedication waiver (http://creativecommons.org/publicdomain/zero/1.0/) applies to the data made available in this article, unless otherwise stated in a credit line to the data. 
(Continued from previous page)

Conclusions: The outcomes of patients with PCNSL treated in our cohort are still poor. In our series, surgical resection might play a role in significantly improving OS and PFS compared with stereotactic biopsy in a subset of patients. The type of surgery and tumour location are prognostic factors for PCNSL.

Keywords: Primary central nervous system lymphoma, Brain biopsy, Resection, Complications, Overall survival, Progression-free survival, prognosis

\section{Background}

Primary central nervous system lymphoma (PCNSL) is a relatively rare and malignant brain tumour, most frequently presenting as diffuse large B-cell lymphoma (DLBCL), which is characterized pathologically by an angiocentric appearance, with lymphoma and inflammatory cells surrounding small blood vessels [1-3]. It is confined to the brain parenchyma, spinal cord, eyes, or leptomeninges but without involvement of systemic disease at the time the patients are diagnosed. Its overall incidence is 0.47 per 100,000 people per year in immunocompetent individuals, with a higher incidence in immunosuppressed patients [4]. The variables of clinical manifestations, imaging features and localization all contribute to the difficulty of making the diagnosis of PCNSL, which can easily be misdiagnosed as other malignancies, such as glioma and brain metastases. We usually perform stereotactic biopsy or craniotomy surgery to confirm the diagnosis. High-dose methotrexate chemotherapy has become the first-line treatment for PCNSL in the last 2 decades because it can cross the blood-brain barrier. Thus, the 5-year survival rate of PCNSL has increased but remains low at 33\% $[5,6]$.

Currently, many scholars have studied the diagnostic procedure, treatment strategies and prognostic factors of PCNSL, but controversies still exist, and the optimal treatment of this disease remains a huge challenge due to the low incidence of PCNSL and the difficulty of conducting large clinical trials. In our study, we retrospectively reviewed patients treated for PCNSL in Tongji Hospital. The aim of the study was to identify the common clinical characteristics and to determine whether there were any differences in surgical outcomes and prognosis between stereotactic biopsied patients and patients who underwent resection.

\section{Materials and methods}

\section{Patient selection and data collection}

This retrospective study was permitted and sponsored by Tongji Hospital, Tongji Medical College, Huazhong University of Science and Technology. By searching the database, 70 patients with histological confirmation of PCNSL admitted to Tongji Hospital between January 1, 2013, and May 31, 2019, were identified. Their medical records were reviewed. Patients were divided into two groups according to the diagnostic procedure: a resection group and a stereotactic biopsy group. We assessed and reviewed the presenting symptoms and signs, Karnofsky performance status (KPS), International Extranodal Lymphoma Study Group (IELSG) score [2], imaging features, treatment outcomes and survival of all patients. Two neurosurgeons in our department independently performed and recorded detailed preoperative evaluations, including a careful history and a physical examination of all patients.

Patients underwent brain magnetic resonance imaging (MRI) on admission. The tumour location, involvement of brain structures, maximum diameter of the lesion, and the number of lesions were recorded. Postoperative complications were classified and recorded according to the Glioma Outcomes Project system, which involves systemic complications, regional complications, and neurologic complications [7].

Based on the experience of our single institution, we chose stereotactic biopsy in patients who were elderly, had a poor general condition, or seemed unlikely to tolerate the surgical resection procedure, or had multiple intracranial neoplasms or deep involved structures. Furthermore, we would consider surgical resection in patients with a good performance status and in a case of a single lesion where resection seemed safe. Additionally, when patients presented with signs of increased intracranial pressure and progressive neurological deficiencies, surgical resection was performed.

\section{Outcome and follow up}

Patients were followed up after hospitalization and received MRI examinations during the follow-up period for the assessment of outcomes. Overall survival (OS) was calculated from the date of the diagnosis to the date of death or censoring. Progression-free survival (PFS) was calculated from the date of diagnosis to the date of disease progression.

\section{Statistical analysis}

Statistical analysis was performed using SPSS Statistics 22.0 (IBM Corporation, Armonk, New York, USA). Clinical characteristics, imaging features and treatment outcomes were compared between the resection and stereotactic biopsy groups. For the description of 
continuous numerical variables, we used the mean \pm standard deviation. The measurements and categorical data were statistically analysed with t-tests and $x^{2}$ tests, respectively. In addition, Fisher's exact test and the Wilcoxon rank-sum test were used for between-group comparisons when appropriate. Probability values $<0.05$ were considered to be statistically significant. We used the Kaplan-Meier method to estimate survival curves, and the log-rank test was used to compare different survival curves. Predictors of selection for resection were identified by using multiple-variable logistic regression. Multivariate analysis of variables with statistical significance in univariate analysis was performed by the Cox proportional hazards model.

\section{Results}

\section{Patient characteristics}

A total of 70 patients were identified, with 40 men (57.1\%) and 30 women (42.8\%). The mean age of the population was $53.3 \pm 14.3$ years, the mean KPS was $77.6 \pm 15.8$, and the mean duration of symptoms was $5.8 \pm 11.2$ months. There were no significant differences in patient age, sex, symptoms and signs or the duration of symptoms between the surgical resection group and the stereotactic biopsy group. The preoperative KPS of the surgical resection group was significantly higher than that of the stereotactic biopsy group (mean $84.3 \pm 16.7$ vs $73.1 \pm 13.7, P=0.002$ ). Moreover, there was a significant difference in the IESLG score between the two groups $(P=0.006)$ (Table 1$)$.

\section{Tumour characteristics}

Thirty-eight patients (54.3\%) had a single lesion, and 32 patients $(45.7 \%)$ had multiple lesions. In the resection group, 23 patients had a single lesion, and 5 patients had multiple lesions. In the stereotactic biopsy group, 15 patients had a single lesion, and 27 patients had multiple lesions. There was a significant difference in the numbers of lesions between the two groups. The mean size of all lesions was $29.9 \mathrm{~mm}: 30.2 \mathrm{~mm}$ in patients who underwent resection and $29.7 \mathrm{~mm}$ in patients who underwent stereotactic biopsy $(P=0.415)$ (Table 1$)$.

\section{Adjuvant therapies}

All patients were given chemotherapy and/or radiotherapy after resection or biopsy. Thirty-two patients (45.7\%) received only high-dose methotrexate-based chemotherapy, 10 patients (14.3\%) were treated with whole-brain radiation therapy alone, and 28 patients (40\%) were given high-dose methotrexate-based chemotherapy with consolidation whole-brain radiation therapy. There was no significant difference in adjuvant therapies between the surgical resection group and the stereotactic biopsy group $(P=0.516)$ (Table 1$)$.

\section{Treatment outcomes}

Complications occurred in 3 cases in the resection group, including 1 patient with intracranial bleeding, 1 with cerebrospinal fluid leak and 1 with meningitis. In the biopsy group, 1 patient experienced intracranial bleeding, and 2 patients experienced seizures. Patients undergoing resection had comparable rates of complications as those undergoing stereotactic biopsy $(10.7 \%$ vs $7.1 \%)$. However, the rate of improvement of symptoms of the resection group was significantly higher than that of the biopsy group (14/28 vs 2/42) (Table 1$)$.

\section{Predictors of selection for resection}

There was no difference favouring biopsy versus resection for sex, duration of symptoms or diameter of the tumours. On single-variable logistic regression, the following factors were significant: age, KPS, IESLG score, single tumour, and not involving deep structures. Multivariable analysis identified a single tumour and not involving deep structures as predictors of selection for resection (Table 2).

\section{Prognosis}

With a median follow-up of 30 months (range 1-110), the mean OS and PFS of all patients were 16.1 months and 6.2 months, respectively. Patients who underwent surgical resection had a mean OS of 23.4 months and a PFS of 8.6 months versus 11.2 months and 4.6 months for those who had a brain biopsy performed (Table 1, Figs. 1 and 2). Table 3 summarizes the results from univariate analyses of $\mathrm{OS}$ and PFS. Younger age, lower IESLG score, not involving deep structures and resection were favourable prognostic factors for OS. In addition, deep structure, resection and no complications were identified as favourable prognostic factors for PFS. Sex, KPS, duration of symptoms, number of tumours, maximum diameter of the target, and changes in symptoms were not significant prognostic factors for survival $(P>$ 0.05). After univariate analysis, multivariable Cox regression analysis was performed with the 5 statistically significant variables, which showed that deep structures not involved and resection were favourable prognostic factors for PCNSL (Table 4). There is a typical example of the resection group in Fig. 3.

\section{Discussion}

PCNSL is defined as an extranodal non-Hodgkin's lymphoma, accounting for $2-5 \%$ of all primary central nervous system neoplasms, with a more aggressive course and a poor prognosis compared with other lymphomas $[6,8,9]$. The clinical characteristics of our patients were consistent with the literature. Their median age was 53.3 years, and there was a male predominance with a sex ratio of $1.33: 1$, which has been 
Table 1 Baseline clinical characteristics, treatment outcomes and prognosis for patients with PCNSL

\begin{tabular}{|c|c|c|c|c|c|}
\hline Characteristics & Resection $(n=28)$ & Biopsy $(n=42)$ & Total $(n=70)$ & $x^{2} / t$ & $P$ value \\
\hline Sex & & & & 0.972 & 0.324 \\
\hline Male & 18 & 22 & 40 & & \\
\hline Female & 10 & 20 & 30 & & \\
\hline Age & $47.9 \pm 15.9$ & $56.9 \pm 12.1$ & $53.3 \pm 14.3$ & 2.686 & 0.995 \\
\hline KPS & $84.3 \pm 16.7$ & $73.1 \pm 13.7$ & $77.6 \pm 15.8$ & -3.068 & 0.002 \\
\hline IELSG score & & & & 10.303 & 0.006 \\
\hline Low risk(0-1) & 16 & 9 & 25 & & \\
\hline Intermediate risk(2-3) & 10 & 22 & 32 & & \\
\hline High risk(4-5) & 2 & 11 & 13 & & \\
\hline \multicolumn{6}{|l|}{ Present symptoms } \\
\hline Headache & 15 & 30 & 45 & 2.333 & 0.127 \\
\hline Limb weakness & 12 & 22 & 34 & 0.610 & 0.435 \\
\hline Mental impairment & 8 & 18 & 26 & 1.469 & 0.226 \\
\hline Aphasia & 3 & 7 & 10 & 0.486 & 0.486 \\
\hline Ataxia & 3 & 5 & 8 & 0.024 & 0.878 \\
\hline Seizure & 2 & 3 & 5 & 0.000 & 1.000 \\
\hline Other & 3 & 2 & 5 & 0.897 & 0.343 \\
\hline Duration of symptoms & $4.3 \pm 7.2$ & $6.9 \pm 13.3$ & $5.8 \pm 11.2$ & 0.945 & 0.826 \\
\hline Numbers of tumors & & & & 14.593 & 0.000 \\
\hline Single & 23 & 15 & 38 & & \\
\hline Multiple & 5 & 27 & 32 & & \\
\hline The maximum diameter of the target & $30.2 \pm 10.6$ & $29.7 \pm 8.7$ & $29.9 \pm 9.5$ & -0.216 & 0.415 \\
\hline Location & & & & 22.451 & 0.000 \\
\hline Deep location & 1 & 16 & 17 & & \\
\hline Infratentorial & 3 & 14 & 17 & & \\
\hline Supratentorial & 24 & 12 & 36 & & \\
\hline Adjuvant therapies & & & & 1.324 & 0.516 \\
\hline Chemotherapy & 14 & 18 & 32 & & \\
\hline Radiotherapy & 5 & 5 & 10 & & \\
\hline Chemotherapy and radiotherapy & 9 & 19 & 28 & & \\
\hline Changes in symptoms & & & & 19.973 & 0.000 \\
\hline Aggravation & 5 & 10 & 15 & & \\
\hline Improvement & 14 & 2 & 16 & & \\
\hline Static & 9 & 30 & 39 & & \\
\hline Complication & & & & 0.273 & 0.601 \\
\hline No & 25 & 39 & 64 & & \\
\hline Yes & 3 & 3 & 6 & & \\
\hline Overall survival & $23.4 \pm 13.0$ & $11.2 \pm 6.2$ & $16.1 \pm 11.2$ & -5.263 & 0.000 \\
\hline Progression-free survival & $8.6 \pm 4.7$ & $4.6 \pm 3.2$ & $6.2 \pm 4.3$ & -4.241 & 0.000 \\
\hline
\end{tabular}

previously seen in many previous large series $[2,3,8$, 10]. PCNSL mostly presents with neurologic impairment symptoms as the first manifestation rather than common B symptoms (fever, weight loss, night sweats). Patients presented with various symptoms based on the CNS site involved, the most common being headache (64.3\%) in our cohort, followed by limb weakness and mental impairment, less frequently presenting with aphasia, ataxia, seizure and other symptoms. Additionally, seizures are relatively uncommon because PCNSL tends to involve 
Table 2 Predictors of selection for resection

\begin{tabular}{|c|c|c|c|c|c|c|}
\hline \multirow[t]{2}{*}{ Independent variable } & \multicolumn{3}{|c|}{ Single variable logistic regression } & \multicolumn{3}{|c|}{ Multiple logistic regression } \\
\hline & $p$ value & OR & $95 \% \mathrm{Cl}$ & $p$ value & OR & $95 \% \mathrm{Cl}$ \\
\hline Sex & 0.436 & 1.47 & {$[0.56,3.84]$} & 0.872 & 1.12 & {$[0.28,4.58]$} \\
\hline Age & 0.016 & 0.95 & {$[0.92,0.99]$} & 0.607 & 0.99 & {$[0.94,1.04]$} \\
\hline KPS & 0.005 & 1.05 & {$[1.02,1.09]$} & 0.122 & 1.04 & {$[0.99,1.08]$} \\
\hline IELSG score & 0.009 & 9.778 & {$[1.76,54.26]$} & 0.462 & 0.08 & {$[0.00,3.87]$} \\
\hline Duration of symptoms & 0.363 & 0.98 & {$[0.92,1.03]$} & 0.344 & 0.95 & {$[0.86,1.06]$} \\
\hline Numbers of tumors & 0.000 & 0.12 & {$[0.04,0.38]$} & 0.016 & 0.17 & {$[0.04,0.72]$} \\
\hline The maximum diameter of the target & 0.819 & 1.01 & {$[0.96,1.06]$} & 0.895 & 0.99 & {$[0.92,1.07]$} \\
\hline Location & 0.000 & 6.91 & {$[2.57,18.58]$} & 0.001 & 6.18 & {$[2.08,18.32]$} \\
\hline
\end{tabular}

deep brain structures. The mean duration of symptoms to diagnosis was 5.8 months in our study.

PCNSL has typical radiological appearances, which often show diffuse homogeneous contrast enhancement and surrounding vasogenic oedema on MRI (Fig. 3). There are also many atypical imaging features that may mimic other diseases and add to the diagnostic difficulty. Recently, various advanced imaging techniques have also been used in the diagnosis and prognostication of PCNS $\mathrm{L}$, including diffusion tensor imaging (DTI), diffusionweighted imaging (DWI) and magnetic resonance spectroscopy (MRS). Toh et al. [11] found that the fractional anisotropy of DTI is significantly lower in PCNSL than in glioblastoma. In addition, PCNSL has markedly higher choline/creatine and choline/ $\mathrm{N}$-acetyl aspartate ratios on MRS than other glial tumours [12]. In our present study, we also observed that the most common location of PCNSL was the supratentorial location (51.4\%), followed by the infratentorial and deep locations $(24.3 \%)$. This is consistent with a retrospective analysis of the clinical data of 100 patients with PCNSL, which was reviewed and analysed by Küker et al [13] At the same time, we found that $65 \%$ of PCNSL patients had solitary lesions, and 35\% had multiple lesions. The mean maximum diameter of the tumour was $29.9 \mathrm{~mm}$.

All of these clinical characteristics enable us to better differentiate PCNSL from other diseases, including gliomas, metastasis, infections and inflammatory demyelinating disease. However, to create favourable conditions for comprehensive follow-up therapy, biopsy or resection must be performed to obtain histopathologic or cytologic confirmation of the diagnosis. A series of studies have been carried out to determine optimal treatment regimens to obtain a better survival benefit for PCNSL patients $[3,10,14,15]$, but there is still controversy. Jahr et al. [16] reported that resection surgery played no role in significantly improving either OS or PFS in PCNSL patients. However, Bellinzona et al. [15] demonstrated that surgery might have a role in a selected subset of patients presenting with large single space occupying lesions and deteriorating neurological status. Cloney et al. [17] suggested that the overall complication rate of resection for PCNSL is comparable to rates for other CNS malignancies and believed that resection is safe for selected patients. In our series of 70 patients, 42 underwent stereotactic biopsy, and 28 underwent surgical

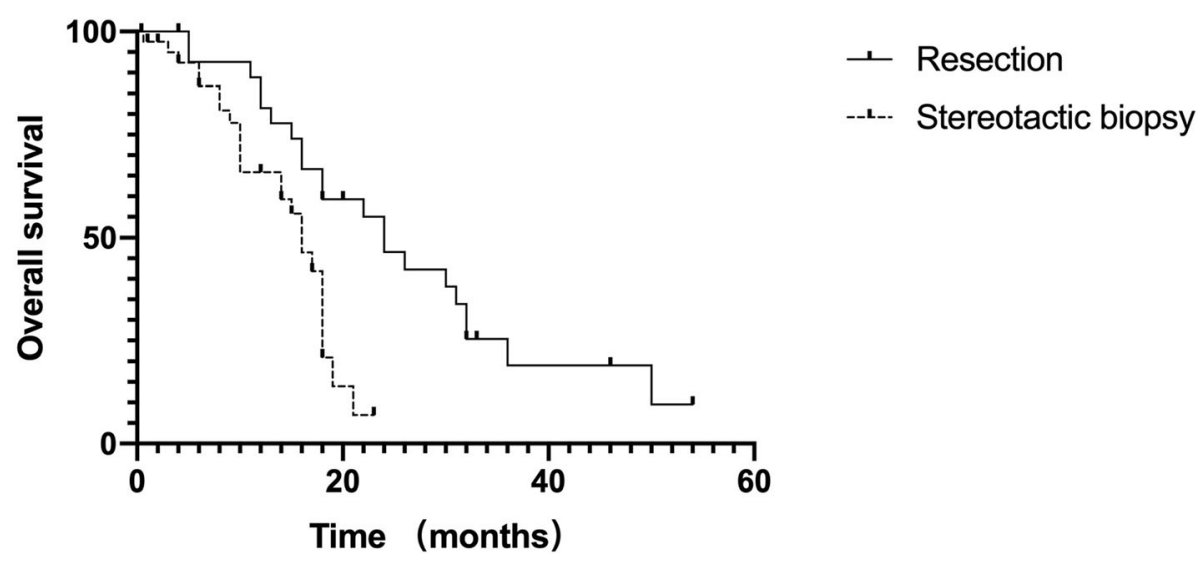

Fig. 1 OS by type of $\operatorname{surgery}(P=0.002)$ 


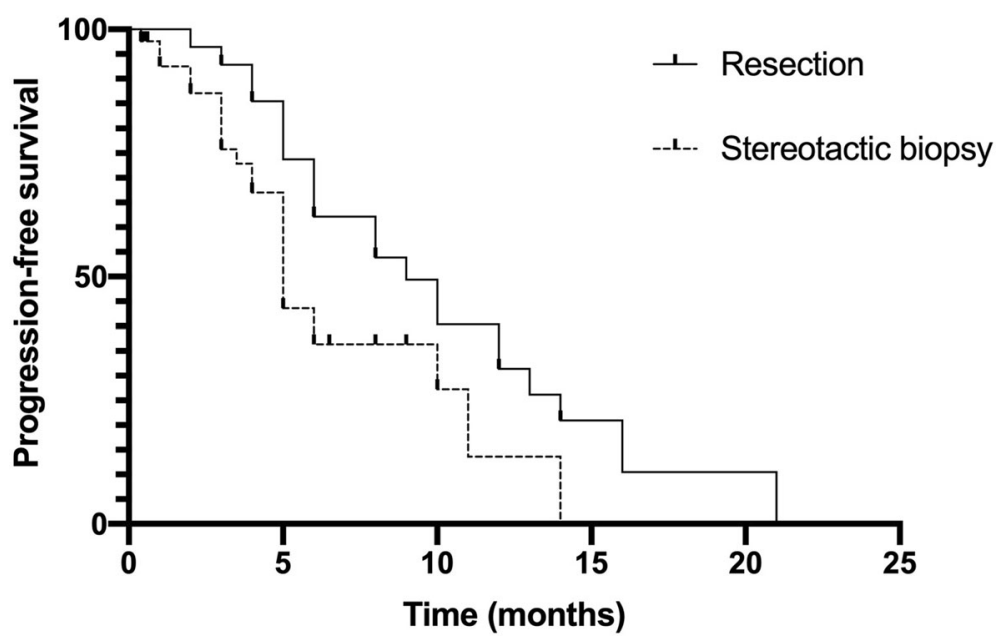

Fig. 2 PFS by type of $\operatorname{surgery}(P=0.038)$

resection. The complication rate was $7.1 \%$ for stereotactic biopsy and $10.7 \%$ for resection, and there was no significant difference. Resection for PCNSL patients has been discouraged and traditionally limited due to an unacceptable morbidity for the procedure according to the literature from the 1970s to 1990s. However, with the development of modern surgical techniques, especially neuronavigation, fluorescein for tumour visualization and intraoperative neurophysiologic monitoring, which have improved the safety and accuracy of surgery, the postsurgical complication rates for PCNSL have decreased to $0-20 \%$, as the recent literature has reported $[10,14,17]$. For example, Cloney et al. [17] reported that the complication rate of the resection group (17.2\%) was lower than that of the biopsy group (28.2\%) through the analysis of 129 patients with PCNSL between 2000 and 2015, and they deemed resection safe for selected patients. Our analysis revealed no significant difference in the complication rate following resection compared to stereotactic biopsy. Our complication rate for resection demonstrates a decrease in comparison with the previously published literature, which was $40 \%$ in PCNSL patients undergoing resection. We also observed that the symptom improvement rate of the resection group was $50 \%$, which was significantly higher than that of the biopsy group (4.8\%). Furthermore, when patients present with signs of increased intracranial pressure and progressive neurological deficits, they would benefit more from surgery than stereotactic biopsy.

In our follow-up study, the mean overall survival was 16.1 months, and the PFS was 6.2 months. In addition, patients who underwent resection had a mean OS of 23.4 months and PFS of 8.4 months, 11.2 months and 4.6 months for those who had a biopsy performed. Weller et al. [18] found that OS and PFS were significantly longer in the resection subset than in biopsied patients through a large randomized phase III study comprising 526 patients. Jahr et al. [16] also reported that patients who underwent resection had an insignificant prolongation of OS compared with patients who had a biopsy performed. In addition, Rae et al. [19] performed a study that involved the largest collective sample of 13,704 patients and showed an increased OS benefit with resection compared with stereotactic biopsy. Our results obtained in both groups are in accordance with those reported in the literature. We speculate that this may be because of the fractional cell killing of cytotoxic drugs, that is, the fewer tumour cells that are present at the start of chemotherapy, the fewer cycles are needed to induce a complete remission. Another reason may be that patients who underwent resection had a reduced likelihood of chemotherapyinduced mutations, which reduced their risk of developing chemotherapy resistance. The prognosis of PCNSL is still poor, and multivariate analysis of various patient characteristics available for most patients identified tumour location and the type of surgery as the only significant prognostic factors for both PFS and OS.

In our study, we also analysed patient characteristics when making management decisions for resection or biopsy. We found that age, KPS, IESLG score, a single lesion, and a not deep lesion location were factors associated with selection for resection on single variable logistic regression. However, in multivariable analysis, we identified that a single tumour and not deep structures were predictors of selection for resection. Our findings are consistent with Cloney et al.'s series of 129 patients with PCNSL [17], which also found that age, multiple lesions and deep lesions influenced selection for resection. Weller et al. [18] also found that patients with a single lesion were likely to undergo resection in their PCNSL series. The guidelines from the European Association only recommend resection when there is a mass effect causing 
Table 3 Univariate Analysis for Overall Survival and Progression-free Survival

\begin{tabular}{|c|c|c|c|c|c|}
\hline & Number & $\begin{array}{l}\text { Overall survival } \\
\text { (months) }\end{array}$ & $\begin{array}{l}P \text { value for } \\
\text { OS }\end{array}$ & $\begin{array}{l}\text { Progression-free survival } \\
\text { (months) }\end{array}$ & $\begin{array}{l}P \text { value for } \\
\text { PFS }\end{array}$ \\
\hline & 70 & $16.1 \pm 11.2$ & & $6.2 \pm 4.3$ & \\
\hline Sex & & & 0.64 & & 0.16 \\
\hline Female & 34 & $15.6 \pm 11.7$ & & $6.7 \pm 4.6$ & \\
\hline Male & 36 & $16.6 \pm 10.8$ & & $5.7 \pm 3.9$ & \\
\hline Age & & & 0.02 & & 0.28 \\
\hline$<60$ & 44 & $18.7 \pm 12.0$ & & $6.4 \pm 4.6$ & \\
\hline$>=60$ & 26 & $11.7 \pm 8.1$ & & $5.8 \pm 3.8$ & \\
\hline KPS & & & 0.10 & & 0.66 \\
\hline$>=70$ & 51 & $16.1 \pm 11.9$ & & $6.2 \pm 4.3$ & \\
\hline$<70$ & 19 & $12.3 \pm 8.0$ & & $6.7 \pm 4.4$ & \\
\hline \multicolumn{6}{|l|}{ IESLG score } \\
\hline Low risk & 25 & $23.0 \pm 12.8$ & 0.001 & $7.5 \pm 5.2$ & 0.138 \\
\hline Intermediate risk & 32 & $13.6 \pm 8.5$ & & $5.7 \pm 3.4$ & \\
\hline High risk & 13 & $9.0 \pm 6.1$ & & $4.8 \pm 4.0$ & \\
\hline Duration of symptoms (months) & & & 0.21 & & 0.22 \\
\hline$>=1$ & 53 & $16.7 \pm 11.5$ & & $6.4 \pm 4.6$ & \\
\hline$<1$ & 17 & $14.2 \pm 10.1$ & & $5.5 \pm 3.1$ & \\
\hline Numbers of tumors & & & 0.99 & & 0.98 \\
\hline Multiple & 32 & $10.6 \pm 7.2$ & & $5.0 \pm 4.0$ & \\
\hline Single & 38 & $20.8 \pm 11.9$ & & $7.1 \pm 4.3$ & \\
\hline $\begin{array}{l}\text { The maximum diameter of the } \\
\text { target }\end{array}$ & & & 0.25 & & 0.10 \\
\hline$>=30$ & 38 & $16.9 \pm 11.8$ & & $6.8 \pm 4.8$ & \\
\hline$<30$ & 32 & $15.1 \pm 10.5$ & & $5.5 \pm 3.6$ & \\
\hline Location & & & 0.00 & & 0.00 \\
\hline Not deep location & 53 & $18.2 \pm 11.7$ & & $6.9 \pm 4.5$ & \\
\hline Deep location & 17 & $9.6 \pm 6.1$ & & $3.8 \pm 2.1$ & \\
\hline The operative type & & & 0.00 & & 0.00 \\
\hline Biopsy & 42 & $11.2 \pm 6.2$ & & $4.6 \pm 3.2$ & \\
\hline Resection & 28 & $23.4 \pm 13.0$ & & $8.6 \pm 4.7$ & \\
\hline Changes in symptoms & & & 0.94 & & 0.96 \\
\hline Not improvement & 54 & $14.9 \pm 11.0$ & & $5.8 \pm 4.0$ & \\
\hline Improvement & 16 & $20.0 \pm 11.4$ & & $7.9 \pm 4.9$ & \\
\hline Complication & & & 0.15 & & 0.00 \\
\hline No & 58 & $16.7 \pm 10.1$ & & $6.9 \pm 4.3$ & \\
\hline Yes & 12 & $13.1 \pm 15.8$ & & $2.8 \pm 1.9$ & \\
\hline
\end{tabular}

Table 4 Multivariate analysis for OS and PFS

\begin{tabular}{ll}
\hline & $\boldsymbol{P}$ value \\
\hline Age & NS \\
IESLG score & NS \\
Deep location & 0.00 \\
The type of surgery & 0.00 \\
Complication & NS \\
\hline
\end{tabular}

herniation [20]. However, Schellekes et al. [21] found that specific subgroups of patients with a solitary PCNSL lesion might gain a survival benefit from resection compared with undergoing only a diagnostic biopsy. Additionally, in light of our findings and considering that surgical resection might benefit additional patients, not just patients with signs of increased intracranial pressure and progressive neurological deficits, because it can help 


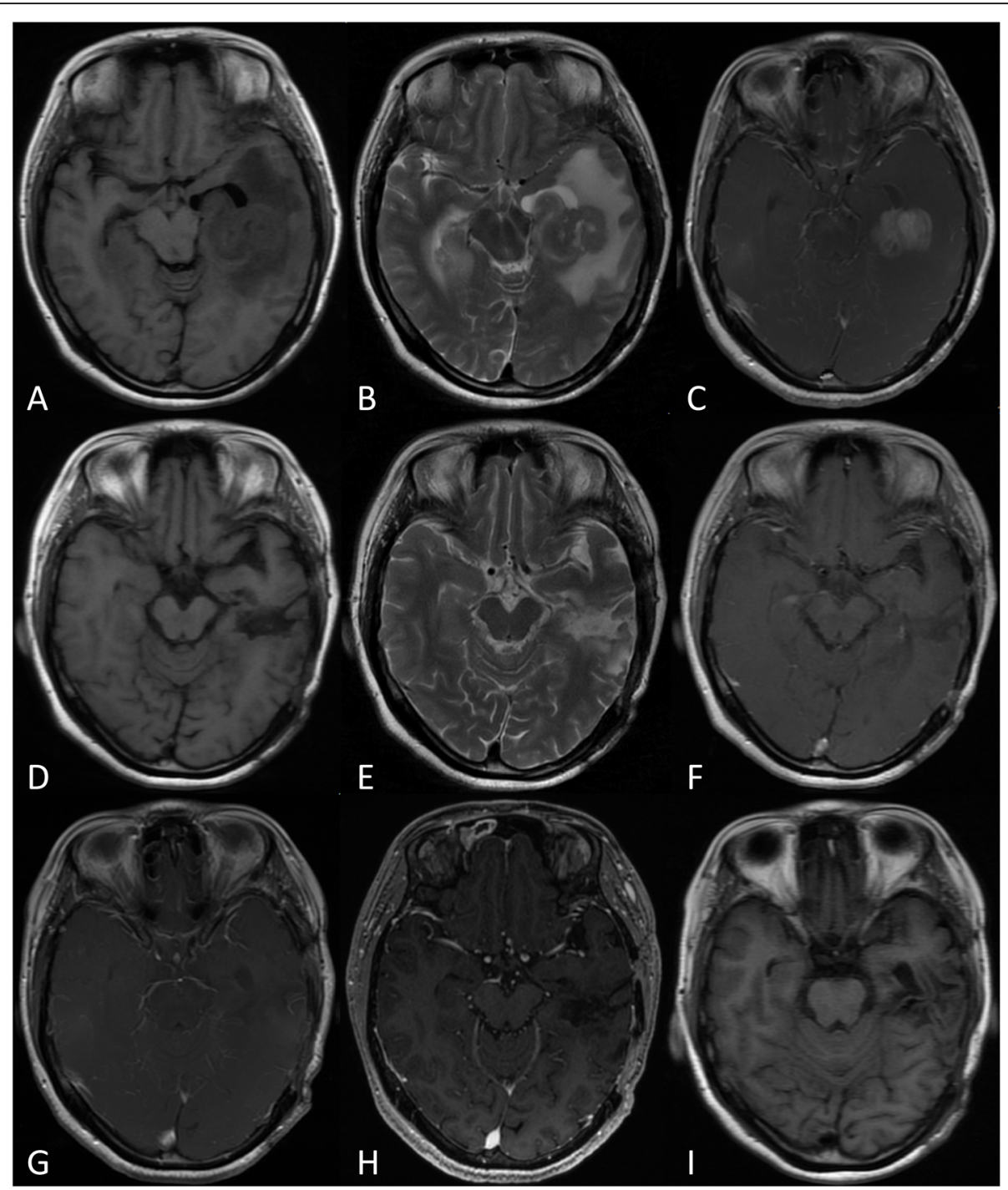

Fig. 3 A 42-year-old men who presented with headache for 1 month. MRI (a, b and $\mathbf{c}$ ) shows a contrast-enhancing solitary lesion with a diameter of $3.5 \mathrm{~cm}$ in the left temporal lobe. He underwent surgery with a craniotomy and gross total resection. The symptoms of headache were improved obviously. MRI examination ( $\mathbf{d}$, e and $\mathbf{f}$ ) was taken at 1 week after surgery, which shows the lesion was removed completely. And MRI of 3 months ( $\mathbf{g})$, half a year $(\mathbf{h})$ and 1 year (i) after surgery show that there was no recurrence of the tumor

patients to relieve symptoms quickly, such as headache, limb weakness, vomiting, etc., which in turn can improve their quality of life and their tolerance of upcoming intensive chemotherapy and radiation treatment. In brief, resection surgery might be better for a selected subset of PCNS $\mathrm{L}$ patients, with better OS and PFS and complication rates comparable to the rates of the biopsy group. When making management decisions for PCNSL patients, we should take individual patient characteristics into account.

There are several limitations of our study. The primary limitations are its retrospective design and the limited number of patients. Moreover, the findings are clearly limited by the presence of selection bias, as described previously, and the lack of multicentre participation. Because of a relatively small analysed study population of our singlecenter, data should be cautiously used. However, we found that surgery might play a positive role in a subset of patients, which suggest the need for further prospective randomized studies to better evaluate the efficacy and safety of surgical resection for PCNSL patients.

\section{Conclusion}

The outcomes of patients with PCNSL treated in our cohort are still poor. In our series, surgical resection might play a role in significantly improving OS and PFS compared with stereotactic biopsy in a subset of patients. The type of surgery and tumor location are the prognostic factors of PCNSL. 


\section{Abbreviations}

PFS: Progression-free survival; OS: Overall survival; PCNSL: Primary central nervous system lymphoma; DLBCL: Diffuse large B-cell lymphoma; KPS: Karnofsky performance status; IELSG: International Extranodal Lymphoma Study Group; MRI: Magnetic resonance imaging; DTI: Diffusion tensor imaging; DWI: Diffusion-weighted imaging; MRS: Magnetic resonance spectroscopy

\section{Acknowledgments}

The authors would like to thank the patients and their families.

\section{Authors' contributions}

KS contributed to the conception and design of this study. SW contributed to data analysis and wrote the manuscript. JW, WJ and TL contributed the data analysis and to modify the article. FH, KZ and WL contributed to the data collection and data interpretation. All authors read and approved the final manuscript.

\section{Funding}

This study was funded by Research-type Clinician funding plan of Tongji Medical College, Huazhong University of Science and Technology (grant No.5001540025), National Natural Science Foundation of China (grant No.81702478 and 81602204). The funding bodies played no role in the design of the study and collection, analysis, and interpretation of data and in writing the manuscript.

\section{Availability of data and materials}

The datasets used and/or analysed during the current study are available from the corresponding author on reasonable request.

\section{Declarations}

\section{Ethics approval and consent to participate}

This study was approved by the Ethical Committee of Tongji hospital, Tongji Medical College, Huazhong University of Science and Technology, China and the research was conducted in full accordance with the World Medical Association Declaration of Helsinki. Written, informed consent was obtained from participants or their respective guardians.

\section{Consent for publication}

Not applicable.

\section{Competing interests}

The authors report no conflict of interest concerning the materials or methods used in this study or the findings specified in this paper.

Received: 6 December 2020 Accepted: 6 May 2021

Published online: 11 May 2021

\section{References}

1. Glass J. Current management of primary central nervous system lymphoma. Chin Clin Oncol. 2017;6(4):38

2. Ferreri AJ, Blay JY, Reni M, et al. Prognostic scoring system for primary CNS lymphomas: the international extranodal lymphoma study group experience. J Clin Oncol. 2003;21(2):266-72.

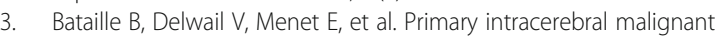
lymphoma: report of 248 cases. J Neurosurg. 2000;92(2):261-6.

4. Han $\mathrm{CH}$, Batchelor TT. Diagnosis and management of primary central nervous system lymphoma. Cancer. 2017;123(22):4314-24.

5. Ostrom QT, Gittleman H, de Blank PM, et al. American brain tumor association adolescent and young adult primary brain and central nervous system tumors diagnosed in the United States in 2008-2012. Neuro Oncol. 2016;18(Suppl 1):i1-i50

6. Olson JE, Janney CA, Rao RD, et al. The continuing increase in the incidence of primary central nervous system non-Hodgkin lymphoma: a surveillance, epidemiology, and end results analysis. Cancer. 2002;95(7):1504-10.

7. D'Amico RS, Cloney MB, Sonabend AM, et al. The safety of surgery in elderly patients with primary and recurrent Glioblastoma. World Neurosurg. 2015; 84(4):913-9.
8. Panageas KS, Elkin EB, DeAngelis LM, Ben-Porat L, Abrey LE. Trends in survival from primary central nervous system lymphoma, 1975-1999: a population-based analysis. Cancer. 2005;104(11):2466-72.

9. Angelov L, Doolittle ND, Kraemer DF, et al. Blood-brain barrier disruption and intra-arterial methotrexate-based therapy for newly diagnosed primary CNS Iymphoma: a multi-institutional experience. J Clin Oncol. 2009;27(21): 3503-9.

10. Jelicic J, Todorovic Balint M, Raicevic S, et al. The possible benefit from total tumour resection in primary diffuse large B-cell lymphoma of central nervous system - a one-decade single-Centre experience. Br J Neurosurg. 2016;30(1):80-5

11. Toh $\mathrm{CH}$, Castillo M, Wong AM, et al. Primary cerebral lymphoma and glioblastoma multiform: differences in diffusion characteristics evaluated with diffusion tensor imaging. AJNR Am J Neuroradiol. 2008;29(3):471-5.

12. Harting I, Hartmann M, Jost $\mathrm{G}$, et al. Differentiating primary central nervous system lymphoma from glioma in humans using localised proton magnetic resonance spectroscopy. Neurosci Lett. 2003;342(3):163-6.

13. Küker W, Nägele T, Korfel A, et al. Primary central nervous system lymphomas (PCNSL): MRI features at presentation in 100 patients. J NeuroOncol. 2005;72(2):169-77.

14. Ouyang T, Wang L, Zhang N, et al. Clinical characteristics, surgical outcomes, and prognostic factors of intracranial primary central nervous system lymphoma. World Neurosurg. 2020;139:e508-16

15. Bellinzona M, Roser F, Ostertag H, Gaab RM, Saini M. Surgical removal of primary central nervous system lymphomas (PCNSL) presenting as space occupying lesions: a series of 33 cases. Eur J Surg Oncol. 2005:31(1):100-5.

16. Jahr G, Da Broi M, Holte H Jr, Beiske K, Meling TR. The role of surgery in intracranial PCNSL. Neurosurg Rev. 2018;41(4):1037-44.

17. Cloney MB, Sonabend AM, Yun J, et al. The safety of resection for primary central nervous system lymphoma: a single institution retrospective analysis. J Neuro-Oncol. 2017:132(1):189-97.

18. Weller M, Martus $P$, Roth $P$, Thiel $E$, et al. Surgery for primary CNS lymphoma? Challenging a paradigm. Neuro Oncol. 2012;14(12):1481-4.

19. Rae Al, Mehta A, Cloney M, et al. Craniotomy and survival for primary central nervous system lymphoma. Neurosurgery. 2019:84(4):935-44.

20. Hoang-Xuan K, Bessell E, Bromberg J, et al. Diagnosis and treatment of primary CNS lymphoma in immunocompetent patients: guidelines from the European Association for Neuro-Oncology. Lancet Oncol. 2015;16(7):e32232.

21. Schellekes N, Barbotti A, Abramov Y, et al. Resection of primary central nervous system lymphoma: impact of patient selection on overall survival published online ahead of print. J Neurosurg. 2021;2021:1-10.

\section{Publisher's Note}

Springer Nature remains neutral with regard to jurisdictional claims in published maps and institutional affiliations.

\section{Ready to submit your research? Choose BMC and benefit from:}

- fast, convenient online submission

- thorough peer review by experienced researchers in your field

- rapid publication on acceptance

- support for research data, including large and complex data types

- gold Open Access which fosters wider collaboration and increased citations

- maximum visibility for your research: over $100 \mathrm{M}$ website views per year

At $\mathrm{BMC}$, research is always in progress.

Learn more biomedcentral.com/submissions 